\title{
Sistem Informasi Akademik Berbasis Mobile Apps Sebagai Media Informasi Akademik Online
}

\author{
Fitri Nuraeni ${ }^{1}$, Ridwan Setiawan ${ }^{2}$, Wijdan Nurhakim ${ }^{3}$, Muhammad Syauqi Mubarok ${ }^{4}$ \\ Jurnal Algoritma \\ Institut Teknologi Garut \\ J1. Mayor Syamsu No. 1 Jayaraga Garut 44151 Indonesia \\ Email : jurnal@sttgarut.ac.id \\ 17itri.nuraeni@itg.ac.id \\ ${ }^{2}$ ridwan.setiawan@itd.ac.id \\ 31706074@itg.ac.id \\ ${ }^{4}$ syauqi.mubarok@itg.ac.id
}

\begin{abstract}
Abstrak - Sistem informasi akademik (SIAKAD) adalah suatu perangkat atau perangkat lunak yang dapat memberikan layanan informasi berupa data siswa, kelas, guru, jadwal siswa dalam pembelajaran, jadwal pengajaran, dan nilai siswa. Saat pembelajaran masih konvensional, siswa berkunjung ke sekolah untuk mendapatkan informasi terkait akademik. Namun sekarang pembelajaran berubah menjadi sistem dalam jaringan (daring/ online), siswa tidak dapat mengunjungi sekolah sehingga hal ini menyulitkan siswa dan orang tuanya untuk mendapatkan informasi tentang informasi akademik. Oleh karena itu, SIAKAD online diperlukan agar siswa atau orang tua dapat dengan mudah memperoleh informasi akademik yang disampaikan oleh pihak sekolah melalui perangkat smartphone. Untuk mengembangkan SIAKAD ini digunakan Rational Unified Process (RUP) dengan tahapan identifikasi awal, intersepsi, elaborasi, konstruksi, dan transisi. Dengan SIAKAD online dapat digunakan untuk mengelola data akademik dan menyampaikan informasi akademik kepada siswa dan orang tua tentang nilai, jadwal pelajaran dan e-raport. Selain itu SIAKAD dapat membantu proses akademik dalam pembelajaran saat ini karena dapat diakses dimana saja dan kapan saja karena aplikasi ini berbasis mobile dan online.
\end{abstract}

Kata Kunci - Mobile; Online; Pembelajaran; Rational Unified Process; Sistem Informasi Akademik.

\section{PENDAHULUAN}

Teknologi smartphone salah satunya perangkat mobile android dapat dijadikan sebagai salah satu basis pengembangan aplikasi karena smartphone lebih mudah dalam mengoperasikannya, bersifat lebih fleksibel, mudah digenggam dan mudah di bawa kemanapun, apalagi saat ini masyarakat lebih sering menggunakan perangkat mobile untuk mengetahui berbagai informasi, termasuk informasi kegiatan belajar mengajar dan informasi mengenai sekolah dan proses akademiknya. Melihat proses pembelajaran di sekolah yang terpaksa harus menggunakan sistem dalam jaringan (daring/ online) sehingga menimbulkan keterbatasan layanan informasi dari pihak sekolah untuk siswa dan orang tua. Sehingga untuk mendukup proses pembelajaran daring saat ini, dibutuhkan sistem informasi akademik (SIAKAD) yang dapat diakses oleh siswa maupun orang tua siswa kapan saja dan dimana saja menggunakan media internet.

Sistem Informasi Akademik (SIAKAD) adalah perangkat lunak yang digunakan untuk menyajikan informasi dan menata administrasi yang berhubungan dengan kegiatan akademis[1], yang dirancang sesuai dengan 
proses bisnis yang berjalan agar dapat meningkatkan kinerja dan pelayanan akademik[2], serta sistem tersebut dapat menyampaikan informasi terkait data akademik yang bersifat sebuah data [3]. Selama ini, dalam pengelolaan data akademik masing banyak yang menggunakan media kertas untuk pelaporan, kemudian direkap dan diinput kembali pada buku raport, namun dengan sistem ini sangatlah rentan terhadap kesalahan baik kesalahan teknik maupun oleh faktor kelalaian manusia[4].

Pada penelitian sebelumnya telah dikembangkan sebuah sistem untuk memberikan informasi kepada mahasiswa dan juga dosen seperti mencetak laporan absen, jadwal dosen mengajar, absen untuk mahasiswa dan juga kelas, kartu untuk perencanaan study, kartu untuk melihat hasil study selama perkuliahan dan juga mencetak jadwal untuk mahasiswa dalam mengikuti kegiatan belajar mengajar[5]. Dalam penelitian lainnya telah dikembangkan atau menciptakan sistem untuk menyampaikan informasi akademik kepada lembaga pendidikan Blessing yang dimana sistemnya dapat di akses menggunakan smartphone android untuk lebih memudahkan pihak lembaga yang dimana sistem pembelajarannya tidak hanya dilakukan secara manual namun juga dapat dilakukan secara online yang dapat di akses di smartphone[6]. Sistem informasi akademik lainnya dikembangkan untuk pengolahan nilai, kemudian hasil pengujian sistem tersebut mencapai angka kepuasan 93,1\% dari ahli sistem, 85,3\% dari ahli substansi dan dan dari siswa mendapatkan 82,4\%, sehingga menjadi sistem informasi akademik berbasis web sangat layak untuk digunakan sebagai sistem dalam mengelola nilai siswa[7].

Maka dengan melihat perkembangan pembelajaran saat ini, perlu dikembangkan sistem informasi akademik berbasis mobile sehingga dapat membantu pihak sekolah dalam mengelola data akademik dan menyajikan informasi yang dapat diakses kapan saja dan dimana saja[8]. Namun, dengan banyaknya proses pengelolaan data oleh pihak sekolah, muncul kebutuhan untuk adanya sistem informasi yang lebih memudahkan input data oleh admin. Dimana pihak sekolah dapat memanfaatkan data akademik dari aplikasi yang sudah ada untuk digunakan pada sistem yang baru, yang lebih mendukung dalam penyajian informasi secara online. Serta memberikan kemudahan bagi siswa dalam mendapatkan informasi akademik yang juga dapat memudahkan kedua orang tua untuk melihat jadwal mata pelajaran siswa dan nilai siswa, penguatan dan dukungan dalam aplikasi tersebut diharapkan mampu membuat siswa dan orang tua siswa tidak lagi kesulitan untuk mendapatkan informasi akademik.

\section{METODE PENELITIAN}

Pada penelitian ini digunakan metode Rational Unified Procces (RUP) yang memiliki tahapan 4 tahapan yaitu inception (permulaan), elaboration (perluasan), contruction dan transition[9]. Metode Rational Unified Process merupakan pendekatan iteratif yang dimana pendekatan ini dilakukan secara berulang, berorientasi arsitektur, terkait kasus, berorientasi aplikasi untuk pengembangan aplikasi[10]. Seluruh pembangunan aplikasi ini dituangkan ke dalam Work Break Down Structure (WBS) pada gambar 1 dibawah ini.

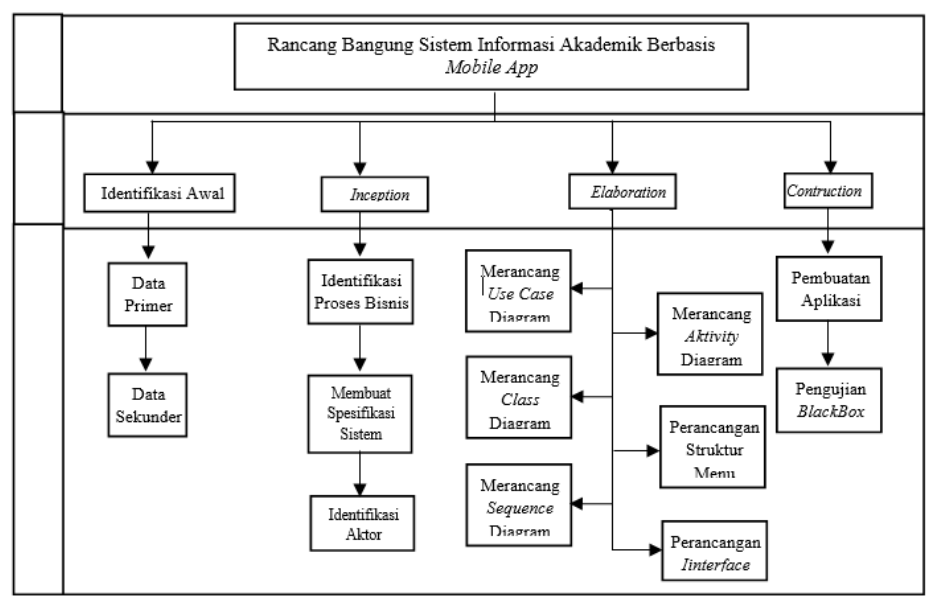

Gambar 1: WBS proses penelitian menggunakan RUP 
Berdasarkan gambar 1 diatas, berikut rincian tahapan penelitian yang dilakukan:

1. Identifikasi Awal, dalam tahapan ini peneliti melakukan pendeskripsian tentang perangkat lunak yang akan dibuat oleh penulis, melakukan pengamatan, analisa dan wawancara, melakukan pengumpulan data yang dilakukan dengan mencari, membaca serta mengumpulkan dokumen-dokumen sebagai referensi seperti buku, artikel, dan literatur-literatur.

2. Inception, pada tahapan ini peneliti melakukan penentuan target aktor yang nantinya akan di gunakan sebagai pengguna dari sistem dan juga menggambarkan hubungan antara pengguna dengan sistem (identifikasi proses bisnis yang di usulkan) dan menggambarkan fungsi serta kinerja dari sebuah sistem yang berbasis komputer dan juga batasan yang mengatur pengembangannya (spesifikasi) dan menjelaskan nformasi hak akses yang akan di berikan pada masing-masing aktor (identifikasi aktor)

3. Elaboration, pada tahapan ini peneliti melakukan pengembangan proses bisnis yang sudah dibuat dan spesifikasi sistem pada tahapan sebelumnya. Adapun hasil dari tahapan sebelumnya akan dimodelkan pada tahapan elaboration yang diantaranya: a) use case diagram yang mengidentifikasi aktor dan skenario; b) activity diagram yang memodelkan aliran kerja dari sebuah sistem; c) sequence diagram yang menggambarkan kelakuan objek yang saling berinteraksi dengan sistem; d) class diagram menggambarkan struktur sistem beserta kelas-kelas yang dibuat agar antara dokumen perancangan dan perangkat lunak dapat sesuai; dan e) merancang struktur menu dan interface sebagai rincian sistem yang berfokus pada bentuk awal tampilan (prototype) akan dibuat.

4. Construction, pada tahap ini dilakukan implementasi kode kedalam bahasa programan yang sesuai dengan pemodelan yang dilakukan pada tahap elaboration, sehingga menghasilkan aplikasi yang siap untuk diuji coba

5. Transition, pada tahap ini dilakukan instalasi sistem, pemeliharaan dan pengujian sistem apakah sudah memenuhi harapan dari user.

\section{HASIL DAN PEMBAHASAN}

\section{A. Interception}

Pada tahapan ini, dilakukan pemahaman tentang apa yang akan di rancang seperti analisis kebutuhan sistem, menentukan aktor-aktor yang terlibat, setelah itu maju ke tahap pembuatan use case diagram dan activity diagram untuk melanjutkan apa yang akan dirancang.

Untuk mendapatkan data primer maka dilakukan wawancara dengan pihak sekolah seperti kepala sekolah, Guru dan juga staff administrasi. Dari data tersebut kemudian dibuat gambaran bagaimana sistem secara keseluruhan melalui proses bisnis yang di usulkan dengan tujuan yaitu untuk menemukan usecase yang dibutuhkan apabila sistem tersebut belum sepenuhnya mengakomodasi kegiatan sistem yang dibutuhkan. Maka dari itu untuk memperoleh hasil analisis kebutuhan sistem ini harus dilakukan proses pengumpulan data sampai menjadi dokumentasi yang lengkap, sehingga dari hasil analisis kebutuhan sistem ini akan terlihat evaluasi yang harus dilakukan pada sistem.

Kemudian untuk proses bisnis dari sistem ini, dapat diindentifikasi beberapa proses yaitu: 1) proses login ke sistem; 2) proses melihat daftar menu; 3) proses memilih menu; 4) proses memasukan data akademik; dan 5) proses penyimpanan data akademik.

Dari penentuan proses bisnis ini kemudian dibuat spesifikasi sistem baru yang akan dibangun yaitu:

a) persyaratan tampilan, aplikasi ini harus memiliki tampilan awal yang mengandung bagian untuk Admin dan user dimana tampilan untuk admin yaitu tampilan login, tampilan menu utama, tampilan data Guru, tampilan data murid, tampilan mata pelajaran, tampilan data kelas, tampilan data nilai dan tampilan jadwal pelajaran.

b) Persyaratan sistem, untuk memenuhi permintaan dari pengguna, di spesifikasi sebagai berikut:

i. $\quad$ spesifikasi fungsional sistem, yang pertama sistem menyediakan fitur input dan impor data untuk 
admin dimana admin dapat melakukan pengeditan atau merubah data jika suatu saat data membutuhkan perbaruan sedangkan untuk user hanya menampilkan fitur untuk melihat saja tanpa bias melakukan perubahan data sehingga terdapat perbedaan akses antara admin dan user

ii. spesifikasi non fungsional sistem, yang pertama kebutuhan perangkat lunak, dibutuhkan perangkat lunak untuk pembuatan aplikasi yaitu untuk web menggunakan bahasa pemrograman PHP sehingga halaman dapat dibuat sehingga klien dapat memintanya [11]. Sedangkan untuk android menggunakan framework flutter yang merupakan teknologi yang berbasis open source dimana aplikasi tersebut dapat digunakan Google untuk membuat aplikasi Android dan iOS[12]. Yang kedua Kebutuhan perangkat keras, dibutuhkan perangkat komputer atau laptop, yang digunakan untuk pembuatan aplikasi ini

c) Persyaratan pengembangan, yaitu menggunakan use case diagram sebagai gambaran interaksi antara pengguna dengan sistem, databasenya diimplementasikan menggunakan XAMPP dan pembangunan web menggunakan bahasa program PHP dan untuk aplikasi berbasis android menggunakan framework flutter.

\section{B. Elaboration}

Pada tahapan elaboration, dilakukan perancangan sistem akademik menggunakan diagram usecase seperti pada gambar 2 dibawah. Pada gambar tersebut, terdapat 3 aktor yaitu Admin, Guru dan Orang Tua yang dapat mengakses sistem dengan akun siswa.

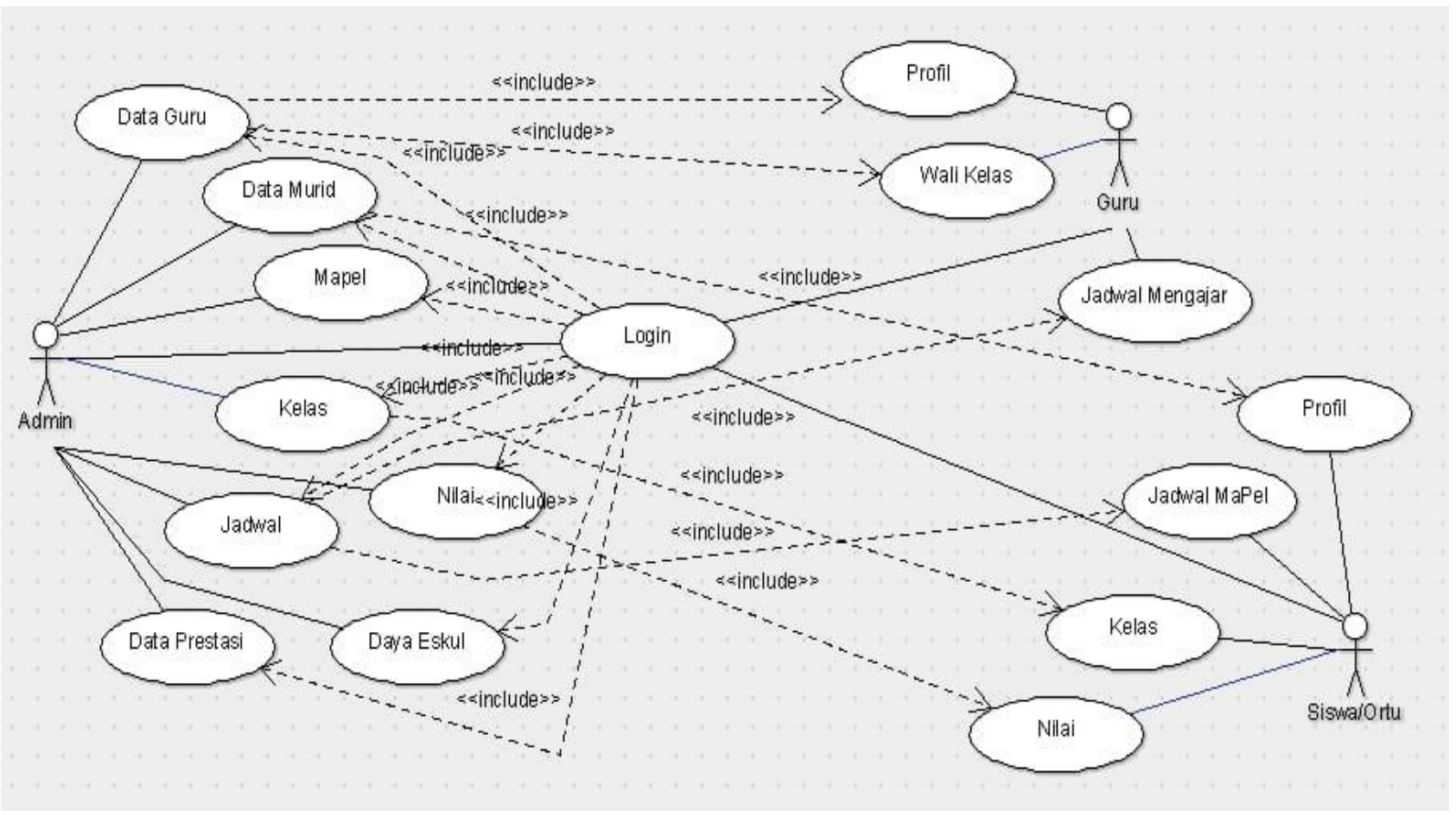

Gambar 2: Usecase Diagram

Untuk dapat melihat setiap proses yang dilakukan oleh aktor terhadap sistem, maka dilakukan pengembangan dalam bentuk diagram use case seperti pada gambar 2 diatas. Dimana kita memiliki 4 usecase seperti yang dijelaskan pada tabel 1 dibawah ini: 
Tabel 1: Identifikasi Use Case

\begin{tabular}{lll}
\hline No & Use Case & Deskripsi \\
\hline 1 & Login & $\begin{array}{l}\text { Admin dan user membuka Sistem Informasi pada semua platform baik website } \\
\text { maupun android lalu melakukan melakukan login dengan menggunakan NIP } \\
\text { (untuk Guru) sedangkan NIS (untuk siswa dan orang tua siswa) dan password }\end{array}$ \\
\hline 2 & $\begin{array}{l}\text { Melihat daftar } \\
\text { menu }\end{array}$ & $\begin{array}{l}\text { Setelah melakukan login maka admin dan user dapat melihat daftar menu yang } \\
\text { tampil di masing-masing platform baik website maupun android }\end{array}$ \\
\hline 3 & Memilih menu & $\begin{array}{l}\text { Setelah melihat daftar menu yang tersedia maka admin dan user dapat memilih } \\
\text { menu yang di inginkan, untuk siswa, Guru dan orang tua siswa mendapatkan } \\
\text { informasi akademik sedangkan admin memilih menu untuk melakukan } \\
\text { pengolahan data }\end{array}$ \\
\hline 4 & Pengolahan data & $\begin{array}{l}\text { Setelah admin memilih menu yang di inginkan admin dapat memulai } \\
\text { melakukan pengolahan data seperti mengiinput data akademik, mengedit } \\
\text { maupun menghapus data akademik agar data tersebut dapat tampil di sistem } \\
\text { berbasis android nantinya }\end{array}$ \\
\hline
\end{tabular}

Pada tahapan ini dirancangan class diagram yang menggambarkan hubungan database dan interfacenya seperti pada gambar 3 dibawah ini:

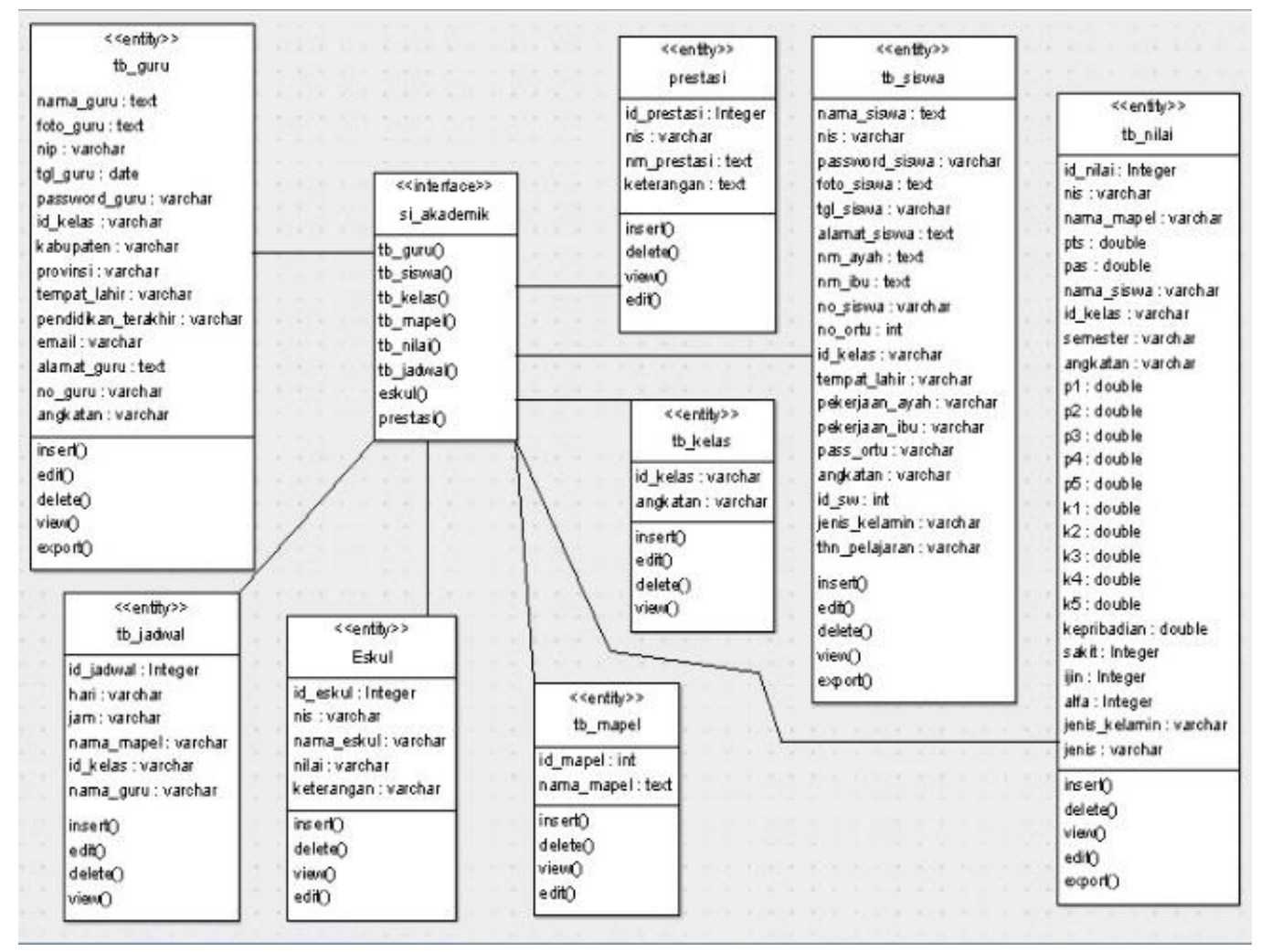

Gambar 3: Class Diagram

\section{Contruction}

Tahapan ini pengimplementasian rancangan layout ke bahasa pemrograman. Berikut adalah tampilan untuk sistem informasi akademik yang dibangun. 

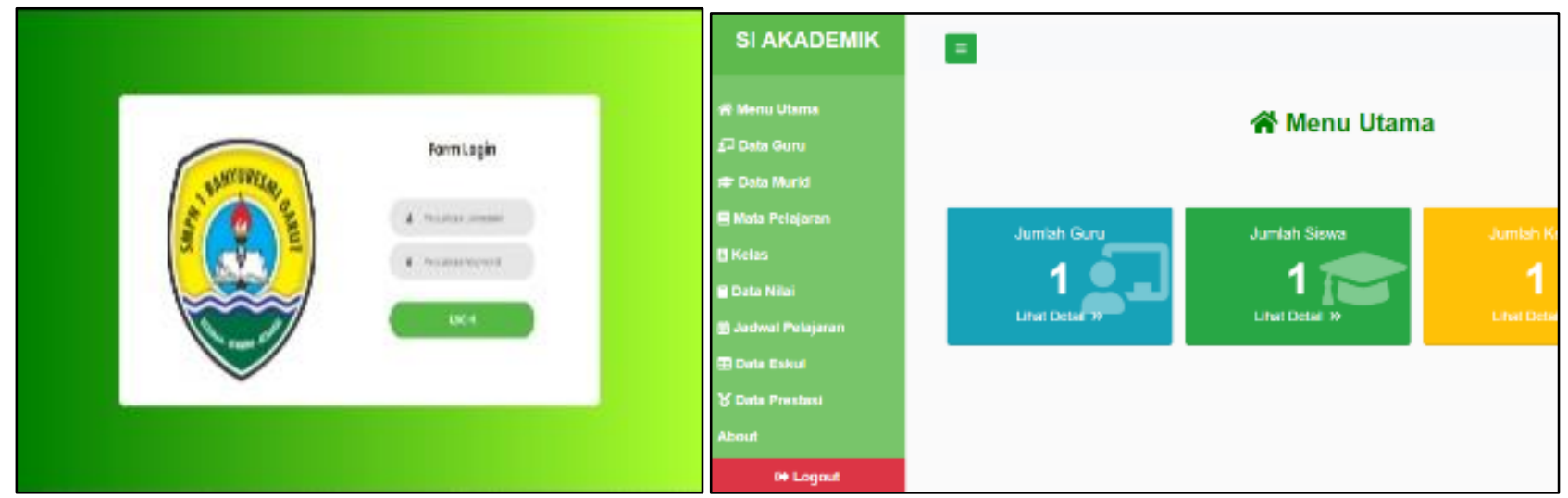

Gambar 4: Tampilan halaman login dan menu utama bagi admin

Untuk admin sekolah diberikan fasilitas login seperti pada gambar 4 sebelah kiri. Saat login berhasil maka, akan dimunculkan halaman dashboard yang memuat menu utama untuk admin. Untuk setiap proses input data ke sistem oleh admin, diberikan fasilitas import data dari excel seperti pada gambar 5 dibawah. Hal ini dimaksudkan agar dapat memudahkan pekerjaan staf administrasi sekolah dalam menyajikan informasi akademik.

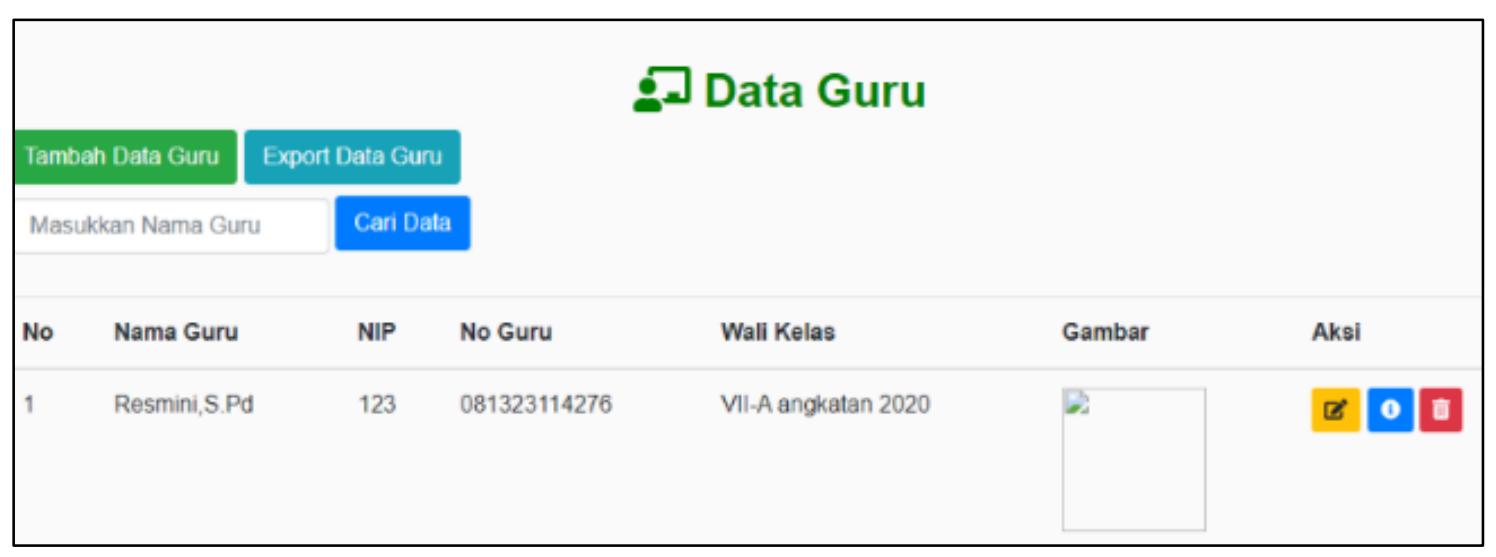

Gambar 5: Tampilan halaman halaman daftar data guru dan fasilitas ekspor data

Sedangkan untuk user yang menggunakan sistem ini seperti siswa, orang tua siswa dan guru menggunakan versi mobile sehingga dapat menggunakan perangkat mobile-nya masing-masing dengan tampilan halaman login seperti gambar 6 .

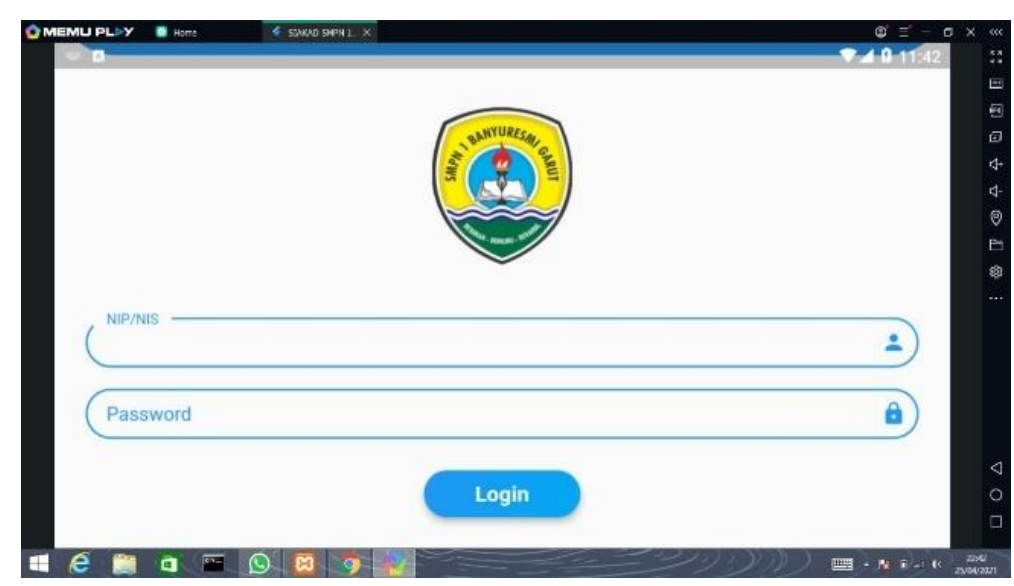

Gambar 6: Tampilan halaman login bagi user 
Untuk guru akan memiliki menu khusus yaitu melihat jadwal mengajar seperti pada gambar 7 dibawah ini.

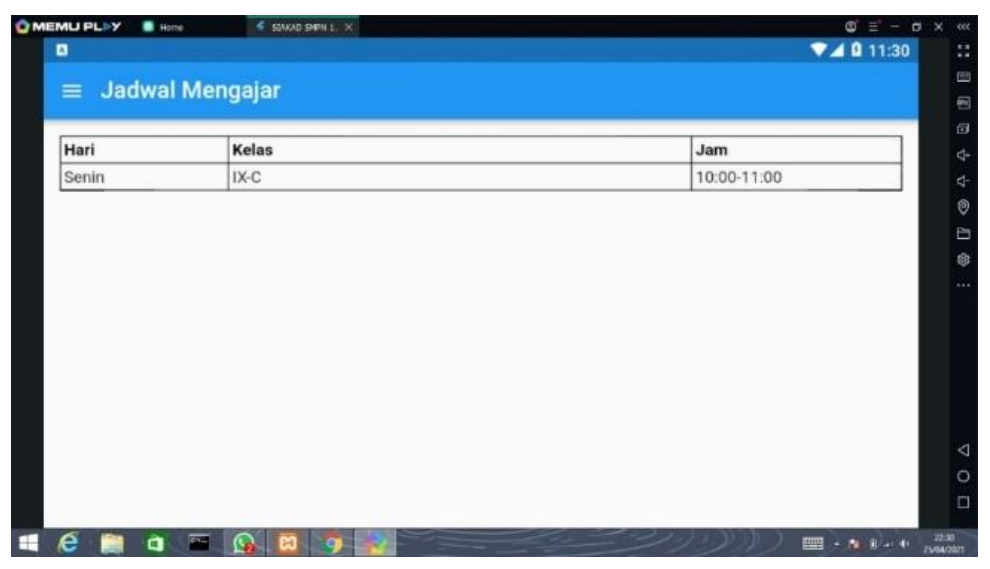

Gambar 7: Tampilan halaman lihat jadwal mengajar

Sedangkan untuk user siswa dan orang tua siswa mengakses halaman yang sama, dengan menu utama seperti profil siswa, kelas, jadwal pelajaran dan nilai dalam format raport seperti pada gambar 8 dibawah ini.
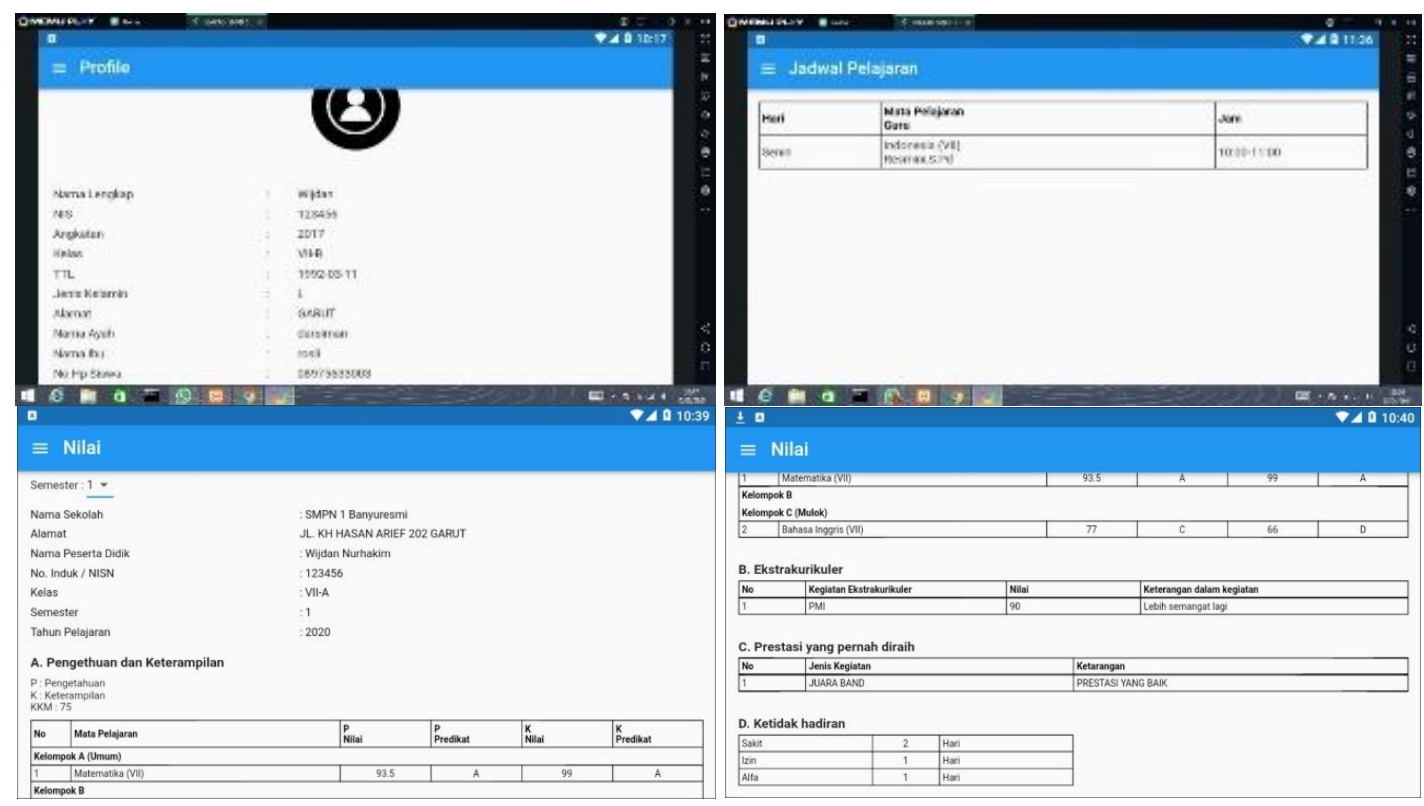

Gambar 8: Tampilan halaman informasi akademik bagi siswa

\section{Transition}

Pengujian blackbox testing dimana pada tahap ini dilakukan pengujian dari kelas-kelas diagram, berfungsi dengan semestinya.

Tabel 2: Deskripsi Pengujian Kelas-kelas Diagram

\begin{tabular}{lllll}
\hline Aktifitas & Kelas Uji & Skenario Uji & Hasil yg diharapkan & Kesimpulan \\
\hline Login & $\begin{array}{l}\text { email dan } \\
\text { password }\end{array}$ & Cek validasi login & $\begin{array}{l}\text { Tidak ada kesalahan dari } \\
\text { email maupun password }\end{array}$ & Sesuai \\
\hline Melihat dan & Data Guru & Menampilkan data & Dapat menampilkan data & Sesuai \\
\hline
\end{tabular}




\begin{tabular}{|c|c|c|c|c|}
\hline Aktifitas & Kelas Uji & Skenario Uji & Hasil yg diharapkan & Kesimpulan \\
\hline \multirow{6}{*}{$\begin{array}{l}\text { memilih } \\
\text { daftar menu } \\
\text { (Admin) }\end{array}$} & & Guru & Guru & \\
\hline & Data Murid & $\begin{array}{l}\text { Menampilkan data } \\
\text { murid }\end{array}$ & $\begin{array}{l}\text { Dapat menampilkan data } \\
\text { murid }\end{array}$ & Sesuai \\
\hline & Mata Pelajaran & $\begin{array}{l}\text { Menampilkan data } \\
\text { mata pelajaran }\end{array}$ & $\begin{array}{l}\text { Dapat menampilkan data } \\
\text { mata pelajaran }\end{array}$ & Sesuai \\
\hline & Kelas & $\begin{array}{l}\text { Menampilkan data } \\
\text { kelas }\end{array}$ & $\begin{array}{l}\text { Dapat menampilkan data } \\
\text { kelas }\end{array}$ & Sesuai \\
\hline & Data Nilai & $\begin{array}{l}\text { Menampilkan data } \\
\text { nilai }\end{array}$ & $\begin{array}{l}\text { Dapat menampilkan data } \\
\text { nilai }\end{array}$ & Sesuai \\
\hline & Jadwal Pelajaran & $\begin{array}{l}\text { Menampilkan data } \\
\text { jadwal pelajaran }\end{array}$ & $\begin{array}{l}\text { Dapat menampilkan data } \\
\text { jadwal pelajaran }\end{array}$ & Sesuai \\
\hline \multirow{8}{*}{$\begin{array}{l}\text { melihat dan } \\
\text { memilih } \\
\text { daftar menu } \\
\text { (user) }\end{array}$} & Menu Utama & $\begin{array}{l}\text { Menampilkan menu } \\
\text { Utama }\end{array}$ & $\begin{array}{l}\text { Dapat menampilkan menu } \\
\text { utama }\end{array}$ & Sesuai \\
\hline & Profil (Guru) & $\begin{array}{l}\text { Menampilkan Profil } \\
\text { Guru }\end{array}$ & $\begin{array}{l}\text { Dapat Menampilkan Profil } \\
\text { Guru }\end{array}$ & Sesuai \\
\hline & Profil (Murid) & $\begin{array}{l}\text { Menampilkan Profil } \\
\text { (Murid) }\end{array}$ & $\begin{array}{l}\text { Dapat Menampilkan Profil } \\
\text { (Murid) }\end{array}$ & Sesuai \\
\hline & $\begin{array}{l}\text { Kelas Wali } \\
\text { (Guru) }\end{array}$ & $\begin{array}{l}\text { Menampilkan kelas } \\
\text { wali (Guru)) }\end{array}$ & $\begin{array}{l}\text { Dapat Menampilkan kelas } \\
\text { wali (Guru)) }\end{array}$ & Sesuai \\
\hline & $\begin{array}{l}\text { Jadwal Mengajar } \\
\text { (Guru) }\end{array}$ & $\begin{array}{l}\text { Menampilkan Jadwal } \\
\text { Mengajar (Guru) }\end{array}$ & $\begin{array}{l}\text { Dapat Menampilkan Jadwal } \\
\text { Mengajar (Guru) }\end{array}$ & Sesuai \\
\hline & Kelas (Murid) & $\begin{array}{l}\text { Menampilkan Kelas } \\
\text { (Murid) }\end{array}$ & $\begin{array}{l}\text { Dapat Menampilkan Kelas } \\
\text { (Murid) }\end{array}$ & Sesuai \\
\hline & $\begin{array}{l}\text { Jadwal Pelajaran } \\
\text { (Murid) }\end{array}$ & $\begin{array}{l}\text { Menampilkan jadwal } \\
\text { pelajaran (Murid) }\end{array}$ & $\begin{array}{l}\text { Dapat Menampilkan jadwal } \\
\text { pelajaran (Murid) }\end{array}$ & Sesuai \\
\hline & Nilai (Murid) & $\begin{array}{l}\text { Menampilkan Nilai } \\
\text { (Murid) }\end{array}$ & $\begin{array}{l}\text { Dapat menampilkan Nilai } \\
\text { (Murid) }\end{array}$ & Sesuai \\
\hline \multirow[t]{6}{*}{$\begin{array}{l}\text { Mengelola } \\
\text { data }\end{array}$} & Data Guru & $\begin{array}{l}\text { input, edit maupun } \\
\text { menghapus data } \\
\text { Guru }\end{array}$ & $\begin{array}{l}\text { Form dan tombol dapat } \\
\text { berfungsi dengan baik dan } \\
\text { data dapat tersimpan di } \\
\text { database }\end{array}$ & Sesuai \\
\hline & Data Murid & $\begin{array}{l}\text { input, edit maupun } \\
\text { menghapus data } \\
\text { murid }\end{array}$ & $\begin{array}{l}\text { Form dan tombol dapat } \\
\text { berfungsi dengan baik dan } \\
\text { data dapat tersimpan di } \\
\text { database }\end{array}$ & Sesuai \\
\hline & Mata Pelajaran & $\begin{array}{l}\text { input, edit maupun } \\
\text { menghapus data } \\
\text { mata pelajaran }\end{array}$ & $\begin{array}{l}\text { Form dan tombol dapat } \\
\text { berfungsi dengan baik dan } \\
\text { data dapat tersimpan di } \\
\text { database }\end{array}$ & Sesuai \\
\hline & Kelas & $\begin{array}{l}\text { input, edit maupun } \\
\text { menghapus data } \\
\text { kelas }\end{array}$ & $\begin{array}{l}\text { Form dan tombol dapat } \\
\text { berfungsi dengan baik dan } \\
\text { data dapat tersimpan di } \\
\text { database }\end{array}$ & Sesuai \\
\hline & Data Nilai & $\begin{array}{l}\text { input, edit maupun } \\
\text { menghapus data nilai }\end{array}$ & $\begin{array}{l}\text { Form dan tombol dapat } \\
\text { berfungsi dengan baik dan } \\
\text { data dapat tersimpan di } \\
\text { database }\end{array}$ & Sesuai \\
\hline & Jadwal Pelajaran & $\begin{array}{l}\text { input, edit maupun } \\
\text { menghapus data } \\
\text { jadwal pelajaran }\end{array}$ & $\begin{array}{l}\text { Form dan tombol dapat } \\
\text { berfungsi dengan baik dan } \\
\text { data dapat tersimpan di } \\
\text { database }\end{array}$ & Sesuai \\
\hline Logout & Keluar & Keluar dari halaman & Akun berhasil keluar & Sesuai \\
\hline
\end{tabular}


Setelah sekolah memiliki sistem informasi khusus yaitu sistem informasi akademik berbasis mobile app dimana dengan adanya sistem ini maka memudahkan admin, siswa, orang tua siswa dan juga guru dalam mendapatkan informasi akademik, dan juga informasi yang di dapatkan dalam bentuk database sehingga rentan akan kehilangan itu dapat diminimalisir. Dengan fasilitas impor data dapat memudahkan pihak sekolah dalam memanfaatkan sistem informasi ini dalam penyajikan informasi akademik dikarenakan telah menggunakan sistem berbasis web maupun android sehingga mudah diakses kapan saja dan dimana saja.

\section{KESIMPULAN}

Dari proses penelitian ini dapat disimpulkan bahwa telah dikembangkannya sistem untuk menyampaikan informasi akademik berbasis mobile yang dapat menyajikan informasi akademik seperti profil siswa, kelas, nilai, jadwal pelajaran, dan prestasi sekolah secara online. Sistem informasi akademik ini memudahkan pekerjaan staf administrasi sekolah dengan adanya fasilitas impor data file excel sehingga input data dapat diambil dari sistem lain yang sudah berjalan dan tidak perlu input satu per satu data. Dengan adanya sistem informasi akademik berbasis mobile dan dapat diakses online ini, dapat mendukung proses pembelajaran daring yang sedang dilakukan saat ini dan dikemudian hari. Beberapa saran bagi pengembang selanjutnya yaitu ditambahkannya fitur lanjutan untuk pengelolaan nilai dan presensi yang lebih rinci.

\section{DAFTAR PUSTAKA}

[1] Marisa, "Rancangan Aplikasi Sistem Informasi Akademik menggunakan Metode Waterfall Berbasis Web," Cendikia, vol. XVIII, pp. 303-308, 2019.

[2] I. Pangaribuan and F. Subakti, "Sistem Informasi Akademik Berbasis Web pada SMK (Sekolah Menengah Kejuruan) Teknologi Industri Pembangunan Cimahi," J. Teknol. Dan Inf., vol. 9, no. 2, pp. 128-137, 2019.

[3] M. R. Alpiandi, "Sistem Informasi Akademik Berbasis Web Di Smp Negeri 2 Kecamatan Gaung Anak Serka," J. Sist., vol. 5, no. 3, pp. 8-13, 2016.

[4] K. Anam and A. T. Muharram, "Analisa Dan Perancangan Sistem Informasi Akademik Berbasis Web Pada Mi Al-Mursyidiyyah Al-'Asyirotussyafi' Iyyah,”'J. Tek. Inform., vol. 11, no. 2, pp. 207-217, 2018.

[5] R. Agusli, S. Sutarman, and A. Irawan, "Perancangan dan Implementasi Sistem Informasi Akademik Berbasis Android," J. SISFOTEK Glob., vol. 9, no. 2, 2019.

[6] M. Susanti, "Perancangan sistem informasi akademik berbasis web pada SMK Pasar Minggu Jakarta," J. Inform., vol. 3, no. 1, 2016.

[7] F. Suryandani, "Pengembangan Sistem Informasi Akademik Berbasis Web Sebagai Sistem Pengolahan Nilai Siswa Di Smk Negeri 1 Kudus," 2016.

[8] S. Wahyuni, R. R. Putra, and C. Wadisman, "Pengembangan Sekolah SMA/SMK Yapim Taruna Marelan Dengan Sistem Informasi Akademik Berbasis Web," INTECOMS J. Inf. Technol. Comput. Sci., vol. 3, no. 1, pp. 52-59, 2020.

[9] A. A. Prabowo and I. G. S. M. Diyasa, "SISTEM INFORMASI PEMBAYARAN KPR DI PT. NAHLA CITRAMULIA GRUP BERBASIS ANDROID DENGAN METODE RUP (RATIONAL UNIFIED PROCESS)," in Prosiding Seminar Nasional SANTIKA Ke-1 2019, 2019, pp. 46-51.

[10] S. Susilowati, "PERANCANGAN SISTEM INFORMASI PEMESANAN MAKAM BARU MENGGUNAKAN METODE RATIONAL UNIFIED PROCESS (Studi kasus pada Taman Pemakaman Umum Joglo Jakarta Barat)," J. Pilar Nusa Mandiri, vol. 13, no. ISSN 1978-1946 \& EISSN 2527-6514, pp. 92-97, 2017.

[11] A. Suprianto and A. A. F. Matsea, "Rancang Bangun Aplikasi Pendaftaran Pasien Online Dan Pemeriksaan Dokter Di Klinik Pengobatan Berbasis Web," J. Rekayasa Inf., vol. 7, no. 1, pp. 48-58, 2018.

[12] A. T. M. Pratama and A. R. Pratama, "Rancang Bangun Aplikasi Android 'Kuliah Apa?' Berbasis Flutter dan TensorFlow Lite," AUTOMATA, vol. 2, no. 1, 2021. 